\title{
Esporos e toxinas de Clostridium botulinum dos tipos C e D em cacimbas no Vale do Araguaia, Goiás ${ }^{1}$
}

\begin{abstract}
Aires M. Souza ${ }^{2 *}$, Dercino F. Marques ${ }^{3}$, Jürgen Döbereiner ${ }^{4}$ e Iveraldo S. Dutra ${ }^{5}$
ABSTRACT.- Souza A.M., Marques D.F., Döbereiner J. \& Dutra I.S. 2006. [Spores and toxins of Clostridium botulinum in raining ponds used as water supply for cattle in pastures in the Araguaia Valley, State of Goiás, Brazil.] Esporos e toxinas de Clostridium botulinum em cacimbas utilizadas como bebedouro de bovinos no Vale do Araguaia, Goiás. Pesquisa Veterinária Brasileira 26(3):133-138. Departamento de Medicina Veterinária, Universidade Federal de Goiás, Goiânia, GO 74001-970, Brazil.E-mail: airesms@vet.ufg.br

The occurrence and distribution of Clostridium botulinum spores and toxins type C and D in 300 ponds, used by cattle for drinking on 130 farms located in 12 municipalities of the Rio Araguaia valley, State of Goiás, Brazil, was evaluated. The presence of spores was determined indirectly by cultivation in culture medium, followed by inoculation and neutralization in mice of samples of the sediment from the bottom of the raining ponds, from superficial soil and from cattle feces collected to its circuit. The toxin presence was evaluated directly by inoculation in mice of the filtered sediment of the ponds, followed by the neutralization in mice with antitoxins $C$ and $D$. The presence of C. botulinum spores was significantly more frequent $(\mathrm{p}<0,05)$ in the cattle feces $(31 \%)$, when compared with the results of the superficial soil samples $(19 \%)$ and the sediments $(10 \%)$. Botulinum toxins of type $\mathrm{C}$ and $\mathrm{D}$ or classified as belonging to the $\mathrm{CD}$ compound were detected in 6 samples (2\%) of the 300 ponds. Of the 130 worked farms, in $122(93,85 \%)$ ponds Clostridium botulinum spores or toxins were found in at least one of the researched variables, whilst ponds on only $8(6,15 \%)$ farms did not present any contamination. Age and depth of the ponds were associated with the frequency of detection of botulinum spores and toxins. The older and shallower the ponds were, the larger was the frequency of isolation of the spores and toxins. The contamination of the ponds in the Araguaia valley with Clostridium botulinum spores and toxins type C and D demonstrates the permanent and growing potential risk for the occurrence of botulism in cattle through drinking water.

INDEX TERMS: Clostridium botulinum, spores, botulinum toxin, botulism, water contamination, ponds, cattle.
\end{abstract}

RESUMO.- Foram avaliadas a ocorrência e distribuição de esporos e toxinas de Clostridium botulinum tipos C e D em 300 cacimbas empregadas como bebedouro de bovinos em 130 propriedades

\footnotetext{
${ }^{1}$ Recebido em 14 de dezembro de 2005.

Aceito para publicação em 18 de janeiro de 2006.

Parte da Tese de Doutorado do primeiro autor, apresentada ao Curso de Pós-Graduação em Epidemiologia Experimental e Aplicada às Zoonoses, Faculdade de Medicina Veterinária e Zootecnia, Universidade de São Paulo.

2 Depto Medicina Veterinária, Escola de Veterinária, Universidade Federal de Goiás, Campus II, Cx. Postal 131, Goiânia, GO 74001-970. *Autor para correspondência: airesms@vet.ufg.br

${ }^{3}$ Agência Rural do Estado de Goiás, Escritório da Agência Rural de Britânia, Rua José Carmelo Pinto 369, Centro, Britânia, GO 76280-000.

${ }^{4}$ Embrapa-CNPAB/Projeto Sanidade Animal, Seropédica, RJ 23890-000.

${ }^{5}$ Depto Apoio, Produção e Saúde Animal, Curso de Medicina Veterinária, Universidade Estadual Paulista (Unesp), Campus de Araçatuba, Rua Clóvis Pestana 793, Araçatuba, SP 16050-680.
}

rurais localizadas em 12 municípios do Vale do Araguaia, Estado de Goiás. A presença de esporos foi determinada indiretamente pelo cultivo em meio de cultura, seguido da inoculação e neutralização em camundongo das amostras de sedimento do interior das cacimbas, e do solo superficial e fezes de bovinos, coletadas ao seu redor. A presença de toxina foi avaliada diretamente pela inoculação em camundongo do sedimento filtrado das cacimbas, também seguida da neutralização em camundongo com antitoxinas $\mathrm{C}$ e D. A presença de esporos de $C$. botulinum foi significativamente maior $(\mathrm{p}<0,05)$ nas fezes de bovinos $(31 \%)$, quando comparadas com os resultados das amostras de solo superficial (19\%) e dos sedimentos (10\%). Foram detectadas toxinas botulínicas dos tipos C, D, ou classificadas como pertencentes ao complexo CD, em seis amostras $(2 \%)$ das 300 cacimbas. Das 130 propriedades trabalhadas, em 122(93,85\%) foram encontrados esporos ou toxinas de Clostridium botulinum em pelo menos uma 
das variáveis pesquisadas, enquanto somente $8(6,15 \%)$ não apresentaram qualquer contaminação $\mathrm{A}$ idade e profundidade das cacimbas estiveram associadas com a frequiência de detecção de esporos e toxinas. Assim, quanto mais velhas e rasas, maior a frequiência do isolamento de esporos e toxinas. A contaminação das cacimbas do Vale do Araguaia goiano com esporos e toxinas do Clostridium botulinum tipos C e D demonstra o risco potencial permanente e crescente para a ocorrência da intoxicação botulínica de origem hídrica nos bovinos.

TERMOS DE INDEXAÇÃO: Clostridium botulinum, esporos, toxina botulínica, botulismo, contaminação hídrica, cacimbas, bovinos.

\section{INTRODUÇÃO}

A pecuária é a principal atividade econômica na região do Vale do Araguaia, no Estado de Goiás. Com predominância de grandes planícies, a região tem poucos mananciais hídricos, dificultando assim a obtenção de água para a dessedentação dos animais, situação agravada pelo aumento do rebanho e pela necessidade de dividir os pastos com a finalidade de racionalizar o manejo alimentar. A solução encontrada pelos produtores foi a construção de bebedouros artificiais no solo, denominados regionalmente como cacimbas, com a finalidade de coletar e armazenar água de chuva e do lençol freático, que é relativamente superficial na região.

Em períodos de estiagem, as cacimbas, construídas exclusivamente com a finalidade de prover água de bebida aos animais, reduzem substancialmente o seu volume de água ou secam. Nessas circunstâncias, quando têm pouca profundidade, pequeno volume de água e presença de matéria orgânica no seu interior, estão ocasionalmente associadas ao denominado "mal das cacimbas", que é uma forma de botulismo devido à ingestão de água contaminada pelas toxinas C e/ou D (Souza et al. 1997). Em outras regiões do país, e em alguns países do hemisfério sul, foram relatados surtos da intoxicação botulínica de origem hídrica (Langenegger \& Döbereiner 1988, Dutra et al. 2001, Kriek \& Odendaal 2004), assim como registrada a contaminação ambiental pelos esporos da bactéria em áreas de ocorrência do botulismo associado à ingestão de água contaminada (Silva et al. 1998)

Partindo-se da hipótese de correlação entre a possível ocorrência de botulismo no rebanho bovino e a prática de oferecimento da água de dessedentação aos animais foi delineado o presente estudo, visando verificar a ocorrência de esporos e toxinas de Clostridium botulinum tipos C e D em cacimbas empregadas como bebedouro de bovinos em pastagens na Região do Vale do Araguaia, Estado de Goiás.

\section{MATERIAL E MÉTODOS}

\section{Localização geográfica e escolha das cacimbas}

A área em estudo abrangeu as microrregiões de São Miguel do Araguaia, Rio Vermelho e Aragarças, mesorregião noroeste do Estado de Goiás, denominada Vale do Araguaia goiano e formada por 23 municípios. Com uma área de $55.840,8 \mathrm{~km}^{2}$ e altitude variando de 250-506 metros, o Vale do Araguaia tem uma população bovina de mais de 6 milhões de animais, perfazendo um total de $34 \%$ da população de bovinos de Goiás. Localizada a oeste e noroeste do Estado de Goiás, entre os paralelos $13^{\circ} 16^{\prime} 30^{\prime \prime}$ e $16^{\circ} 25^{\prime} 37^{\prime \prime}$ de latitude

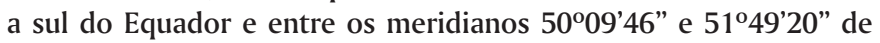

longitude oeste de Greenwich, a região tem como limite oriental o Rio Araguaia, que divide o Estado de Goiás do Mato Grosso do Sul e Mato Grosso (Anuário Estatístico do Estado de Goiás 1996). Nessa região foram localizadas, por conveniência, 300 cacimbas no período de maio a outubro dos anos de 1998 e 1999, em 130 propriedades rurais de 12 municípios. Por ocasião da visita à propriedade foram anotadas as informações, obtidas dos proprietários ou administradores, sobre a idade aproximada das cacimbas trabalhadas. A profundidade média foi calculada com base na medição em quatro pontos centrais da cacimba.

\section{Coleta de material das cacimbas}

A condição para a coleta de material nas cacimbas foi a de que ainda contivesse água. De cada cacimba foram coletadas amostras de sedimento do seu interior e do solo superficial e de fezes de bovinos ao seu redor, de um raio máximo de cerca $30 \mathrm{~m}$, tendo-se como referência a margem da coleção de água.

Sedimento. Foram coletadas cinco amostras de sedimento, de pontos equiidistantes no interior da cacimba, contendo cada uma um volume aproximado de $1000 \mathrm{ml}$. Para esta operação foi empregada uma draga Petersen Grab, devidamente higienizada entre as coletas. Das cinco amostras, juntadas e homogeneizadas, foram coletados $500 \mathrm{ml}$ em frascos estéreis, devidamente identificados. No processo de coleta, transporte e armazenamento até as análises laboratoriais, as amostras foram mantidas sob refrigeração.

Solo superficial. Foram coletadas cinco amostras de solo superficial de pontos eqüidistantes em torno da cacimba, cada uma constituída de $500 \mathrm{~g}$, utilizando-se coletores cuidadosamente limpos com gaze e álcool após cada procedimento. Das cinco amostras, homogeneizadas conjuntamente em sacos plásticos, foram coletados $500 \mathrm{~g}$ para a tentativa de detecção de esporos.

Fezes de bovinos. Foram coletadas pelo menos cinco amostras de fezes ressequidas de bovinos de locais diferentes e de pontos equiidistantes em torno das cacimbas. As amostras de fezes foram acondicionadas em sacos plásticos, devidamente identificadas e transportadas para o laboratório acondicionadas em caixotes de madeira até a realização dos testes laboratoriais. Para o processamento laboratorial foram empregadas apenas as partes internas dos bolos fecais ressequidos, separadas manualmente.

\section{Deteç̧ão de esporos de Clostridium botulinum}

A tentativa de detecção de esporos da bactéria foi efetuada nas amostras de sedimento, do solo superficial e das fezes de bovinos pelo método indireto, ou seja, pelo cultivo do material em meio de cultura Wright e posterior inoculação do sobrenadante em camundongos, obedecendo as normas do Center for Disease Control (CDC) e de acordo com a metodologia empregada por Souza (1985). As amostras de sedimento $(5 \mathrm{ml})$, do solo superficial $(2 \mathrm{~g})$ e de fezes de bovinos $(2 \mathrm{~g})$ foram semeadas em cinco meios de cultura cada uma. Após o aquecimento em banho-maria a $80^{\circ} \mathrm{C}$, durante uma hora, os meios inoculados foram incubados por cinco dias a $35^{\circ} \mathrm{C}$. Em seguida, foram centrifugados e filtrados em placas de Seitz EK. Os filtrados identificados foram acondicionados em frascos estéreis e mantidos congelados a $15^{\circ} \mathrm{C}$ até a realização do bioensaio em camundongos para deteç̧ão de toxina botulínica. Culturas não neutralizadas pelos tipos $C$ ou $D$ não foram tipificadas e foram desconsideradas no presente estudo. A positividade da amostra foi dada quando em pelo menos das cinco repetições foi detectado indiretamente esporos da bactéria.

\section{Detecção de toxina botulínica no sedimento das cacimbas}

As amostras de sedimento foram processadas para a tentativa de deteç̧ão de toxina botulínica. Após a homogeneização do sedimento coletado alíquotas de $20 \mathrm{ml}$ (por amostra) foram 
centrifugadas a $1500 \mathrm{~g}$ durante 10 minutos. O sobrenadante foi filtrado em placas de Seitz EK, acondicionado em frasco estéril, identificado com número geral de ordem e mantido congelado a $-15^{\circ} \mathrm{C}$ até a realização do bioensaio em camundongo para a tentativa de detecção de toxina botulínica. A positividade da amostra foi dada quando em pelo menos das cinco repetições de cada amostra foi detectada a presença e toxina botulínica.

\section{Bioensaio e neutralização em camundongo}

Alíquotas de $0,5 \mathrm{ml}$ do filtrado de cada material a ser analisado foram inoculadas pela via intraperitoneal em três camundongos da raça Swiss, linhagem Webster, pesando entre 17 e 22 g. Outras alíquotas de $0,5 \mathrm{ml}$ dos mesmos materiais foram aquecidas a $100^{\circ} \mathrm{C}$, durante 10 minutos, para a inativação da toxina botulínica eventualmente presente. Após o resfriamento, foram inoculadas em camundongos. Todos os testes foram realizados em duplicatas e o período de observação dos camundongos foi de 76 horas. Materiais suspeitos de conterem a toxina botulínica foram submetidos à soroneutralização com antitoxinas botulínicas tipos C e D (Center for Disease Control, Atlanta, EUA), conforme descrito por Souza (1985), e a tipificação foi dada pela neutralização com a antitoxina homóloga. A amostra foi classificada como pertencente ao complexo CD quando ocorreu a neutralização com as duas antitoxinas testadas.

\section{Análise estatística}

As amostras foram obtidas por conveniência, conforme descrição de Triola (1999). Para efeitos de cálculos a quantidade de cacimbas na região foi estimada em 10.000 nos anos de 1998-1998. Para o tamanho da amostra, objetivando-se dentre outros aspectos as proporções, 0 erro adotado foi no máximo de $6 \%$ e, nesse caso, empregou-se o programa estatístico denominado Statdisk (Triola 1999). Os testes de significância adotados foram os teste t de Student (paramétrico) e os testes não-paramétricos de Wilcoxon e $\mathrm{c}^{2}$. A teoria dos quadrados mínimos também foi aplicada para ajustar aos dados de uma regressão linear simples. $O$ nível de significância usado no presente trabalho foi de $5 \%$ de probabilidade $(\alpha=0,05)$.

\section{RESULTADOS E DISCUSSÃO}

Uma característica marcante da bovinocultura desenvolvida no Vale do Araguaia goiano é o emprego das águas de cacimbas na dessedentação dos animais. Essa prática que viabilizou inicialmente o desenvolvimento da pecuária na região, não despertou anteriormente qualquer preocupação sobre os seus possíveis reflexos na sanidade bovina. Adotadas como uma solução prática, as cacimbas predominam na quase totalidade dos sistemas extensivos de produção da região, que contam com mais de 6 milhões de bovinos. No entanto, sob o ponto de vista sanitário as cacimbas representam risco potencial, especialmente quando relacionadas com as enfermidades de transmissão fecal-oral.

Souza et al. $(1996,1997)$ relacionaram a ocorrência do botulismo hídrico no Vale do Araguaia, associando-o às cacimbas contendo elevado teor de matéria orgânica, incluindo restos de animais em decomposição. Com base nessas observações e registros foi desenvolvido o presente estudo, que teve por objetivo avaliar a contaminação ambiental de cacimbas localizadas em propriedades rurais no Vale do Araguaia goiano pelo Clostridium botulinum e toxinas C e D.

No período compreendido entre os meses de maio e outubro dos anos de 1998-1999, foram avaliadas 300 cacimbas empregadas na dessedentação dos animais, em 130 propriedades
Quadro 1. Microrregiões e municípios do Vale do Araguaia goiano em que foram coletadas amostras do sedimento de 300 cacimbas, do solo superficial ao seu redor e de fezes de bovinos encontradas nas suas proximidades

\begin{tabular}{ccc}
\hline Microregião & Município & $\begin{array}{c}\text { Número de cacimbas } \\
\text { pesquisadas }\end{array}$ \\
\hline São Miguel do Araguaia & São Miguel do Araguaia & 8 \\
& Mundo Novo & 8 \\
& Nova Crixás & 43 \\
& Crixás & 5 \\
Rio Vermelho & Mozarlândia & 6 \\
& Araguapaz & 7 \\
& Aruanã & 159 \\
& Britânia & 22 \\
& Jussara & 27 \\
Aragarças & Itapirapuã & 2 \\
& Santa Fé de Goiás & 7
\end{tabular}

Quadro 2. Resultados da tipificação de esporos e toxinas de Clostridium botulinum tipo C e D detectados em materiais coletados de $\mathbf{3 0 0}$ cacimbas no Vale do Araguaia goiano

\begin{tabular}{lllll}
\hline Material & \multicolumn{2}{l}{ Tipos de esporos e toxinas } & \multirow{2}{*}{ Total } \\
\cline { 2 - 3 } & $\mathrm{C}$ & $\mathrm{D}$ & $\mathrm{CD}$ & \\
\hline Esporos & & & & \\
$\quad$ Sedimento & 06 & 08 & 16 & 30 \\
$\quad$ Solo superficial & 28 & 11 & 18 & 57 \\
$\quad \begin{array}{l}\text { Fezes } \\
\text { Toxinas }\end{array}$ & 22 & 16 & 55 & 93 \\
$\quad$ Sedimento & 01 & 01 & 04 & 06
\end{tabular}

rurais dedicadas à pecuária de corte, localizadas em 12 municípios do Vale do Araguaia goiano (Quadro 1). Das 300 cacimbas, 225(75\%) tinham idade média igual ou acima de 15 anos e 75 (25\%) haviam sido construídas entre 1 e 14 anos. A área média das cacimbas trabalhadas foi de $482,29 \mathrm{~m}^{2}$, sendo a área mínima de $30 \mathrm{~m}^{2}$ e a máxima $2826 \mathrm{~m}^{2}$. O desvio padrão das áreas das cacimbas foi de $510,85 \mathrm{~m}^{2}$, e o intervalo de confiança (IC=95\%) para a média populacional foi igual a $424,48 \mathrm{~m}^{2}<\mu<540,10 \mathrm{~m}^{2}$. A profundidade média (nível de água) das cacimbas foi de $1,83 \mathrm{~m}$, com o valor mínimo de $0,5 \mathrm{~m}$ e máximo de $4,0 \mathrm{~m}$.

Das 130 propriedades trabalhadas, em $122(93,85 \%)$ foram encontrados esporos ou toxinas de $C$. botulinum em pelo menos uma das variáveis pesquisadas, enquanto somente $8(6,15 \%)$ não apresentaram qualquer contaminação. $O$ intervalo de confiança, a $95 \%$ de certeza para a proporção populacional, indicou que $90-98 \%$ das cacimbas das propriedades visitadas tinham esporos ou toxinas de $C$. botulinum.

Em 30 (10\%) amostras de sedimento das cacimbas (Quadro 2) foi possível o isolamento de esporos de $C$. botulinum dos tipos $\mathrm{C}$ (2\%), D (2,67\%) ou CD (5,33\%). Com intervalo de confiança de $95 \%$, a proporção populacional foi de $0,006<p<0,134$, ou seja, entre 6,6 e $13,4 \%$ dos sedimentos da cacimbas continham esporos da bactéria. Apenas duas amostras não pertencentes aos tipos C ou $\mathrm{D}$, e não tipificadas, foram encontradas no sedimento das cacimbas.

Nas amostras de solo superficial, coletadas ao redor das cacimbas, 57 (19\%) foram consideradas positivas para a presença de esporos de $C$. botulinum (Quadro 2) dos tipos C $(9,33 \%)$ ou D 
$(3,67 \%)$ ou do complexo $\mathrm{CD}(6 \%)$. Com intervalo de confiança a $95 \%$ de certeza para a proporção populacional, pode-se afirmar que a contaminação do solo por $C$. botulinum foi de $0,15<p<0,23$, ou seja, entre 15 e $23 \%$ das amostras de solo superficial em torno das cacimbas continham esporos da bactéria. A proporção de esporos da bactéria no solo superficial foi estatisticamente superior à encontrada nas amostras do sedimento das cacimbas $(p<0,05)$. Três amostras de solo positivas no bioensaio em camundongo, não neutralizadas pelas antitoxinas empregadas, não foram tipificadas.

Das 300 amostras de fezes de bovinos, coletadas ao redor das cacimbas, 93(31\%) continham esporos de C. botulinum (Quadro 2). $O$ intervalo de confiança ( $I C=95 \%$ ) foi de $0,26<p<0,36$, ou seja, entre 26 e $36 \%$ das fezes de bovinos continham esporos da bactéria, classificados como sendo pertencentes aos tipos $\mathrm{C}$ $(7,33 \%), D(5,33 \%)$ ou ao complexo CD (18,33\%). Nessa situação, a proporção de esporos da bactéria nas fezes de bovinos foi estatisticamente superior à encontrada nas amostras dos solos superficiais e da mesma forma à dos sedimentos $(\mathrm{p}<0,05)$. A ingestão de esporos da bactéria pelos animais ocorre em ambientes contaminados, principalmente quando pastejam em áreas próximas de cadáveres decompostos, como relatado por Souza \& Langenegger (1987).

A presença de toxina botulínica foi detectada em seis amostras $(2 \%)$ de sedimento, das quais quatro pertencentes ao complexo $\mathrm{CD}$ e duas aos tipos $\mathrm{Ce} \mathrm{D}$ (Quadro 2). Nessa condição, com IC $=95 \%$, entre 0,4 e 3,6\% dos sedimentos das cacimbas pesquisadas continham toxina botulínica. Considerando que a proporção de ocorrência de esporos de $C$. botulinum no sedimento foi estatisticamente inferior à da sua ocorrência no solo superficial e fezes, somente foi aplicado o teste $\mathrm{Z}$ para testar a hipótese nula de que a proporção de ocorrência de toxinas de $C$. botulinum nos sedimentos é igual à proporção de ocorrência dos esporos nos sedimentos, versus a hipótese alternativa de que essas proporções são diferentes. $\mathrm{O} Z$ calculado, igual a 4,13 , foi superior ao tabelado $(1,96)$, indicando que a proporção de toxinas nos sedimentos foi estatisticamente inferior à de esporos nesse mesmo substrato $(\mathrm{p}<0,05)$.

A profundidade média das cacimbas no momento de coleta das amostras também teve correlação com a presença de esporos e toxinas. Quando distribuídas em dois grupos de cacimbas, contaminadas e não contaminadas, as médias de profundidade

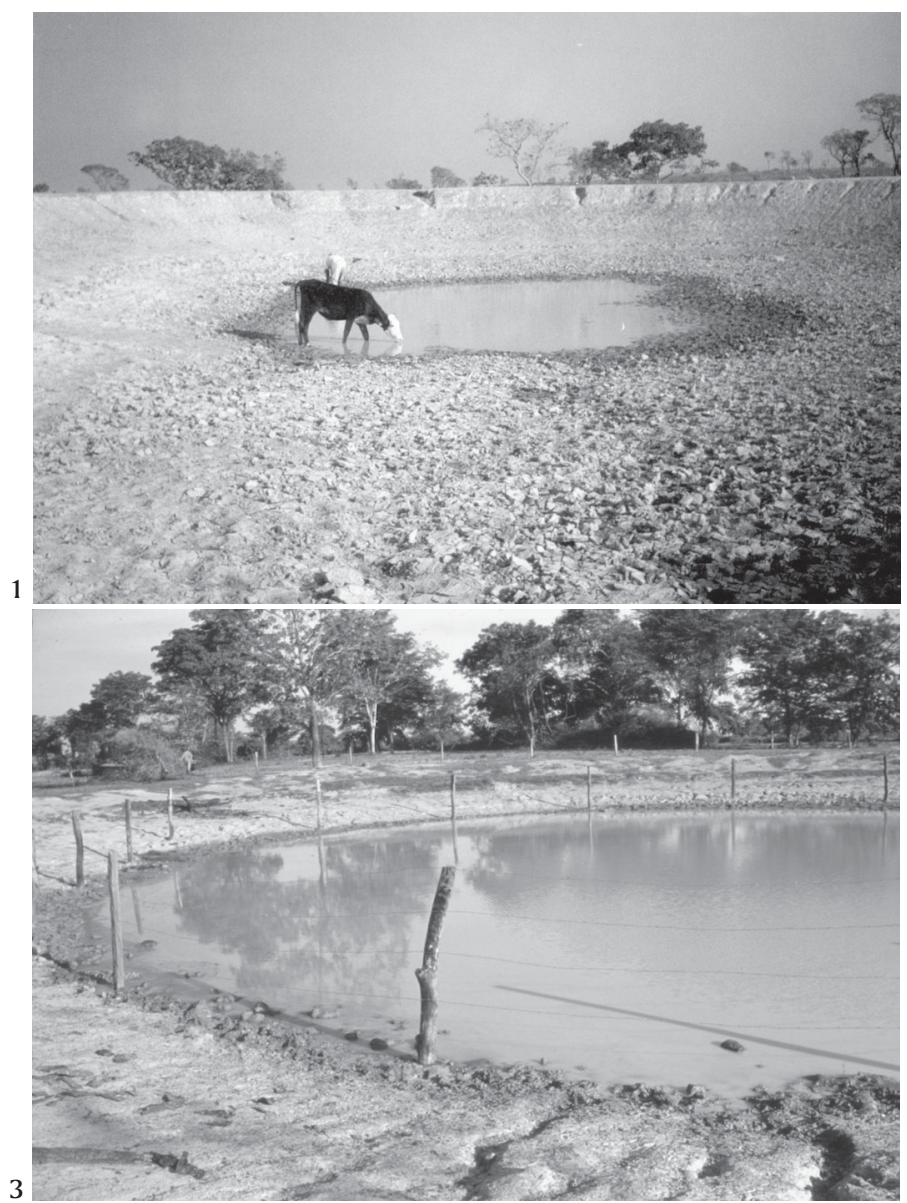

Fig.1. Bovino no interior de cacimba em processo de secagem no Vale do Araguaia goiano.

Fig.3. Cerca construída com a intenção de impedir o acesso de bovinos à cacimba.

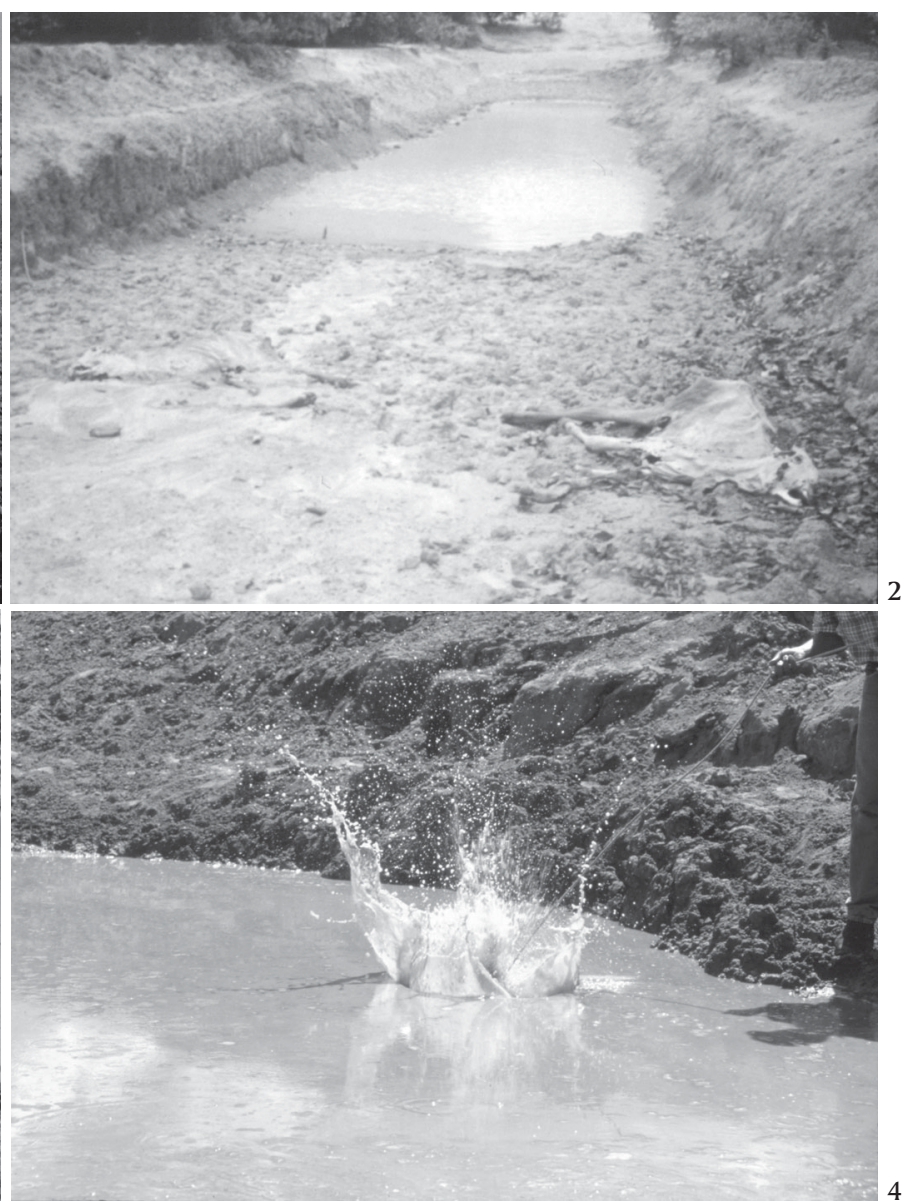

Fig.2. Cadáveres de bovinos no interior de cacimba.

Fig.4. Coleta de sedimento de cacimba com emprego da draga Petersen Grab. 
foram de 1,13 e 1,92m, com desvio padrão de 0,4371 e 0,6283, respectivamente. Pelo teste $t$ de Student e $Z$ de Wilcoxon, ao nível de $5 \%$ de probabilidade, houve a indicação de que o nível da água influenciou na ocorrência de esporos ou toxinas, ou seja, quanto menor o nível da água, maior a probabilidade da sua ocorrência. Uma idéia das variações dos níveis de água encontrados e das condições das cacimbas por ocasião do desenvolvimento dos trabalhos pode ser obtida nas Fig.1-4.

Quando avaliada a relação entre a porcentagem de cacimbas com o sedimento contaminado por esporos ou toxinas com a sua idade, a indicação é que ocorreu um aumento proporcional da contaminação ambiental por $C$. botulinum de $0,91 \%$ nas cacimbas para cada ano de idade $(\mathrm{p}<0,05)$. Dessa forma, esperase que, num prazo de 25 anos, $22,95 \%$ das cacimbas estejam contaminadas por toxinas ou esporos da bactéria. Tal fato pôde ser comprovado, pois, das 14 cacimbas com 25 anos, $3(21,43 \%)$ estavam contaminadas.

De particular interesse foi a associação entre a idade das cacimbas e a ocorrência de esporos. Na medida em que se tornam mais velhas aumenta significativamente $(p<0,05)$ a chance das cacimbas estarem contaminadas. Esse fato deve-se provavelmente à frequiência com que os animais contendo esporos nas suas fezes defecam ao redor das cacimbas ou mesmo dentro delas. Esse pressuposto decorre da constatação de que houve diferença significativa no número de amostras de fezes de bovinos contaminadas com esporos, quando comparado com as amostras de solo superficial e sedimento. Não se pode excluir também a possibilidade de que ocorra a contaminação inicial das cacimbas pelas fezes de bovinos e que a perpetuação da bactéria seja determinada pelas condições favoráveis ou não de multiplicação bacteriana no seu interior.

Estudos recentes relataram que $C$. botulinum tipo $\mathrm{D}$ cresce satisfatoriamente em um sistema in vitro composto por solo, fezes de bovinos e água de chuva (Ferreira 2002), o mesmo não ocorrendo com o tipo C. Isto posto, as condições existentes na região indicam não somente a contaminação ambiental pela bactéria e toxinas $C$ e $D$, mas também a possibilidade concreta de os animais estarem eventualmente ingerindo a toxina botulínica. Cabe ainda ressaltar que a metodologia empregada na tentativa de detecção da toxina por meio da inoculação em camundongos tem limitações práticas conhecidas, principalmente devido à sua baixa sensibilidade toxicológica e epidemiológica (Dutra 2001), o que certamente restringiu a caracterização da real contaminação ambiental. Por outro lado, estes resultados refletem apenas a situação no momento da coleta.

Embora a ingestão de doses subletais da toxina botulínica (tipo B) esteja associada à diminuição na produção de leite e aumento na contagem de células somáticas de bovinos leiteiros (Yeruham et al. 2003), são desconhecidos os danos causados ao gado de corte. No entanto, pode-se deduzir que a ingestão contínua, mesmo de dose subletal, tenha como consequiência o aumento da susceptibilidade dos animais a uma eventual intoxicação letal. Na realidade, o fato de bovinos criados extensivamente e não vacinados contra o botulismo apresentarem anticorpos contra as toxinas C e D (Gregory et al. 1996) revela que este é um evento comum em áreas endêmicas.

De fato, e ao que tudo indica, os tipos C e D estariam envolvi- das nos surtos associados à intoxicação botulínica de origem hídrica (Dutra et al. 2001). Situação de risco potencial, semelhante à descrita por esses autores, também pôde ser observada por ocasião das visitas às propriedades, em que cadáveres de bovinos permaneciam em decomposição dentro de cacimbas ou mesmo na sua proximidade (Fig.2). No entanto, durante os trabalhos não foram relatados pelos produtores problemas recentes de mortalidade de bovinos nessas áreas.

Condição epidemiológica análoga à encontrada no presente estudo também foi descrita por Silva et al. (1998), que constataram a alta contaminação ambiental por esporos de $C$. botulinum dos tipos C e D em amostras de solo, do limo de coleções de água e nas fezes de búfalos, coletadas em áreas alagadiças da Baixada Maranhense. Nessa região também ocorreram surtos de intoxicação botulínica em búfalos, associados epidemiologicamente à ingestão hídrica (Langenegger \& Döbereiner 1988).

Os resultados do presente estudo devem ser analisados no contexto da evolução epidemiológica do botulismo em bovinos no Brasil e os seus reflexos sanitários e ambientais. A ocorrência em larga escala do botulismo associado à deficiência de fósforo (Tokarnia et al. 1970, Döbereiner et al. 1992, Dutra 2001) e a destinação inadequada dos cadáveres intensificaram a contaminação ambiental pelo microrganismo, tendo como consequiência a ocorrência de surtos associados a diversos alimentos (Dutra 2001, Dutra et al 2005) e à água contaminada (Dutra et al. 2001). Por ocasião do desenvolvimento do trabalho pôde-se observar que os produtores cercam as cacimbas (Fig.3) com a finalidade de impedir o acesso dos animais. Esse comportamento, baseado em observações empíricas, está cada vez mais comum no Vale do Araguaia e revela a necessidade de se garantir o fornecimento seguro de água aos animais.

\section{REFERÊNCIAS}

Anuário Estatístico do Estado de Goiás 1996. Secretaria do Planejamento e Desenvolvimento Regional, Goiânia. 198p.

Döbereiner J., Tokarnia C.H., Langenegger J. \& Dutra I.S. 1992. Epizootic botulism of cattle in Brazil. Dtsch. Tierärztl. Wochenschr. 99(5):188190.

Dutra I.S. 2001. Epidemiologia, quadro clínico e diagnóstico pela soroneutralização em camundongos do botulismo em bovinos no Brasil, 19892001. Tese de Livre Docência, Curso de Medicina Veterinária, Unesp, Campus de Araçatuba, São Paulo. 133p.

Dutra I.S., Döbereiner J., Rosa I.V., Souza L.A.A. \& Nonato M. 2001. Surtos de botulismo em bovinos no Brasil associados à ingestão de água contaminada. Pesq. Vet. Bras. 21(2):43-48.

Dutra I.S., Döbereiner J. \& Souza A.M. 2005. Botulismo em bovinos alimentados com cama de frango. Pesq. Vet. Bras. 25(2):115-119.

Ferreira R.M.M. 2002. Contaminação ambiental por Clostridium botulinum tipos C e D de valas de captação hídrica e cultivo do microrganismo em um sistema experimental. Dissertação, Unicamp, Campinas, São Paulo. $58 \mathrm{p}$.

Gregory A.R., Ellis T.M., Jubb T.F., Nickels R.J. \& Cousins D.V. 1996. Use of enzyme-linked immunoassays for antibody to types $C$ and $D$ toxins for investigations of botulism in cattle. Aust. Vet. J. 73(2):55-61.

Kriek N.P.J. \& Odendaal M.W. 2004. Botulism, p.1885-1902. In: Coetzer J.A.W. \& Tustin R.C. (ed.) Infectious Diseases of Livestock. Oxford Press, Cape Town.

Langenegger J. \& Döbereiner J. 1988. Botulismo enzoótico em búfalos no Maranhão. Pesq. Vet. Bras. 8(1/2):37-42. 
Silva T.M.D, Dutra I.S., Castro R.N. \& Döbereiner J. 1998. Ocorrência e distribuição de esporos e toxinas de Clostridium botulinum tipos C e D em áreas de criação de búfalos na Baixada Maranhense. Pesq. Vet. Bras. 18(3/ 4):127-131.

Souza A.M. 1985. Distribuição de esporos de Clostridium botulinum no solo em torno de cadáveres decompostos de bovinos vítimas de botulismo em pastagens no sul de Goiás. Dissertação, UFMG, Belo Horizonte, Minas Gerais. 66p.

Souza A.M. \& Langenegger J. 1987. Esporos de Clostridium botulinum em torno de cadáveres decompostos de bovinos em pastagens no sul de Goiás. Pesq. Vet. Bras. 7(1):17-22.
Souza A.M., Marques D.F. \& Dutra I.S. 1996. Botulismo enzoótico bovino de origem hídrica em Goiás. Anais XXIV Congr. Bras. Med. Veterinária, Goiânia, Goiás, p.74. (Resumo)

Souza A.M., Marques D.F. \& Dutra I.S. 1997. Mal das Cacimbas. Anais XXV Congr. Bras. Med. Veterinária, Gramado, Rio Grande do Sul, p.164. (Resumo)

Tokarnia C.H., Langenegger J., Langenegger C.H. \& Carvalho E.V. 1970. Botulismo em bovinos no Piaú, Brasil. Pesq. Agropec. Bras. 5:465-472.

Yeruham I., Elad D., Avidar Y., Grinberg K., Tiomkin D. \& Monbaz A. 2003 Outbreak of botulism type B in a dairy cattle herd: clinical and epidemiological aspects. Vet. Rec. 153:270-272. 